\title{
On the effect of water and oxygen in chemical vapor deposition of boron nitride
}

\author{
Henrik Pedersen, Mikhail Chubarov, Hans Högberg, Jens Jensen and Anne Henry
}

\section{Linköping University Post Print}

N.B.: When citing this work, cite the original article.

Original Publication:

Henrik Pedersen, Mikhail Chubarov, Hans Högberg, Jens Jensen and Anne Henry, On the effect of water and oxygen in chemical vapor deposition of boron nitride, 2012, Thin Solid Films, (520), 18, 5889-5893.

http://dx.doi.org/10.1016/j.tsf.2012.05.004

Copyright: Elsevier

http://www.elsevier.com/

Postprint available at: Linköping University Electronic Press

http://urn.kb.se/resolve?urn=urn:nbn:se:liu:diva-79682 
On the effect of water and oxygen in chemical vapor deposition of boron nitride

Henrik Pedersen*, Mikhail Chubarov, Hans Högberg, Jens Jensen, Anne Henry

Department of Physics, Chemistry and Biology,

Linköping University, SE-581 83 Linköping, Sweden

*Corresponding author; e-mail: henke@ifm.liu.se

Phone: +46132868 47

Fax: +4613137568 


\section{Abstract}

Growth studies of $\mathrm{sp}^{2}$-hybridized boron nitride (BN) phases by thermal chemical vapor deposition (CVD) are presented; of particular interest is the presence of oxygen and water during growth. While Fourier transform infrared spectroscopy reveals the presence of B-N bonds and elemental analysis by elastic recoil detection analysis shows that the films are close to stoichiometric, although containing a few atomic percent oxygen and hydrogen, $\mathrm{X}$ ray diffraction measurements show no indications for nucleation of any crystalline BN phases, despite change in N/B-ratio and/or process temperature. Thermodynamic modeling suggests that this is due to formation of strong B-O bonds already in the gas phase in the presence of water or oxygen during growth. This growth behavior is believed to be caused by an uncontrolled release of water and/or oxygen in the deposition chamber and highlights the sensitivity of the BN CVD process towards oxygen and water.

Keywords: Boron nitride; Chemical Vapor Deposition; water; oxygen

\section{Introduction}

Boron and nitrogen are neighboring atoms to carbon in the periodic table. As such, they exhibit similar valence electronic structure properties as carbon. Hence, the BN binary system contains a $\mathrm{sp}^{2}$ hybridized phase analogue to graphite, hexagonal BN (h-BN). In addition, there is a $\mathrm{sp}^{2}$ hybridized rhombohedral phase $(\mathrm{r}-\mathrm{BN})$ and less ordered turbostratic BN (t-BN). Two $\mathrm{sp}^{3}$ hybridized phases: cubic BN (c-BN), with cubic symmetry as diamond and 
a wurtzitic phase (w-BN) of hexagonal symmetry that is a BN counterpart to Lonsdaleite (hexagonal diamond).

The close relationship in phase distribution seen between $\mathrm{BN}$ and carbon is also reflected by the properties shown by each respective allotrope, albeit with important differences. For instance, h-BN is like graphite a soft lubricous material, but whereas graphite is an electrically conducting material $\mathrm{h}-\mathrm{BN}$ is a semiconductor with a band gap of $5.2 \mathrm{eV}[1]$ and a thermal conductivity of $150-200 \mathrm{Wm}^{-1} \mathrm{~K}^{-1}$ [2]. The $\mathrm{sp}^{3}$ allotropes of $\mathrm{BN}$ share both the hardness and semiconductor properties of diamond $[3,4]$. However, as p-doping of diamond has proven to be difficult both $\mathrm{n}$ and $\mathrm{p}$-doping of $\mathrm{BN}$ are possible. Despite these very promising semiconductor properties, BN is the least investigated of the III-N semiconductor materials given the difficulties in growing high quality films of particularly c-BN.

For the deposition of the $\mathrm{sp}^{3}$-hybridized phases, highly energetic techniques such as RF and magnetron sputtering, ion-plating and ion-beam assisted deposition (IBAD) [4, 5] or plasma enhanced chemical vapor deposition (PECVD) techniques such as electron cyclotron resonance PECVD or microwave PECVD [6] are commonly applied. These processes promote a bombardment of the growing film by atoms and/or ions, which is regarded as necessary, at least initially, to nucleate c-BN. The bombardment gives rise to high degree of compressive stress in the films that in the worst case causes spallation of the films and is likely to degrade the electronic properties of the films. Further, the deposition of c-BN films often follows a growth mode, where a thin, few $\mathrm{nm}$, amorphous film is nucleated closest to the substrate, which is followed by a few $\mathrm{nm}$ of t-BN before any c-BN can nucleate [7]. Such layered growth must be avoided to obtain films of high quality c-BN. 
For the deposition of the $\mathrm{sp}^{2}$-hybridized phases, a thermal chemical vapor deposition (CVD) process is often used. Recently a number of reports on the growth of h-BN film by CVD has been published; epitaxial growth on sapphire [8] and nickel (111) substrates [9], was demonstrated and in the later case a $500 \mathrm{~nm}$ thick $\mathrm{h}-\mathrm{BN}$ film exhibited a near band gap UV luminescence at $227 \mathrm{~nm}$, showing the possibility to use h-BN in optical applications.

In this study, we investigate the growth of $\mathrm{sp}^{2}$-hybridized $\mathrm{BN}$ phases for semiconductor applications by thermal CVD, using a precursor mixture consisting of triethyl boron (TEB), $\mathrm{B}\left(\mathrm{C}_{2} \mathrm{H}_{5}\right)_{3}$ and ammonia, $\mathrm{NH}_{3}$ in hydrogen carrier gas. Of particular interest is the presence of impurities, oxygen and water, during growth and their origin. Our results from Fourier transform infrared spectroscopy (FT-IR) show the presence of B-N bond, but no support for nucleation of any crystalline BN phases is found from XRD despite change in N/B-ratio and/or process temperature. Thermodynamic modeling suggests that this is due to formation of strong B-O bonds already in the gas phase. Time of flight energy elastic recoil detection analysis (ToF-E ERDA) also shows that the films are close to stoichiometric, but contains a few atomic percent oxygen and hydrogen. This growth behavior is believed to be caused by an uncontrolled release of water and/or oxygen in the deposition chamber originating from the used susceptor.

\section{Experimental details}

In this study a hot wall CVD reactor was used for the synthesis of boron nitride thin films. In the hot wall CVD concept, at least both floor and ceiling of the susceptor, i.e. the growth chamber of the CVD reactor, are heated, thus creating a very uniform heat distribution. Often in the growth of epitaxial semiconductor films, the susceptor is made from high 
density and high purity graphite that is inductively heated by an applied RF-field induced by a current in a copper coil around the susceptor. The hot wall concept for growth of silicon carbide and III-nitrides has been described in detail elsewhere [10, 11]. In this study, a susceptor specially modified for the growth of boron nitride was used, schematized in Fig. 1. The susceptor consisted of an inner growth chamber made from hot pressed hexagonal BN, and high density graphite blocks over and under this chamber. These graphite blocks are inductively heated by the RF-field induced in the copper coil; the heat was then transferred to the BN chamber by the thermal conduction. The whole susceptor was surrounded by low density graphite insulation and the susceptor pack placed in a quartz tube. This design was adopted to minimize the risk of contamination of the BN films by primarily carbon released from the graphite susceptor when heated, but also to avoid contamination of the BN films by impurities in the graphite such as Ti, Fe and S.

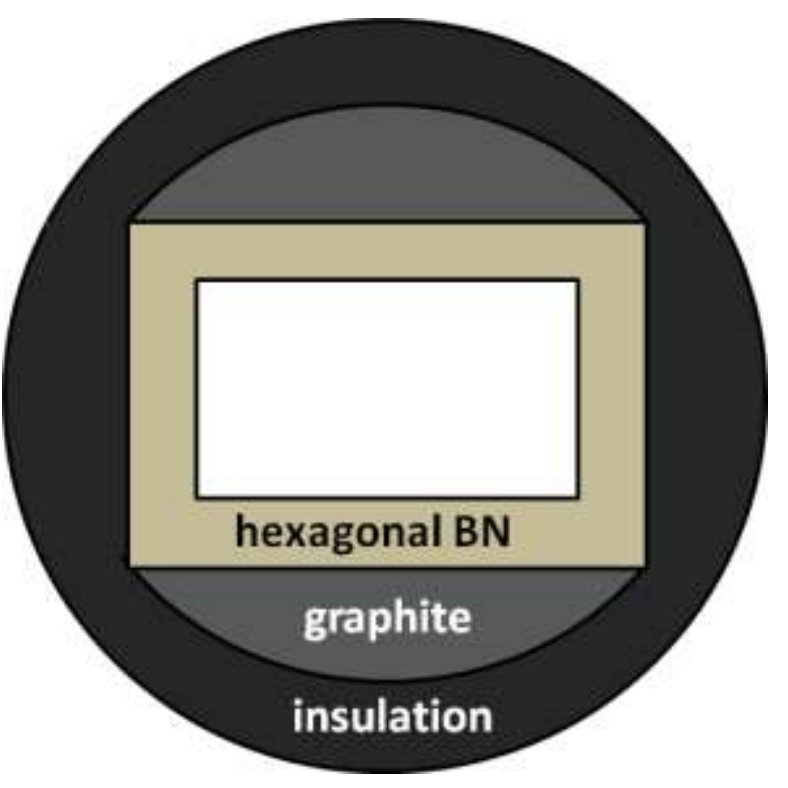

Figure 1: Schematic cross section of the susceptor used in this study. 
Prior to deposition, the reactor is pumped down to a base pressure in the low $10^{-4} \mathrm{~Pa}\left(10^{-6}\right.$ mbar) range with a turbo molecular pump. In this study, triethyl boron, $\mathrm{B}\left(\mathrm{C}_{2} \mathrm{H}_{5}\right)_{3}$, (TEB) of semiconductor grade and ammonia (99.999 \%) are used as the boron and nitrogen precursor, respectively. The precursors are diluted in hydrogen gas, purified by palladium membrane, to a $\mathrm{B} / \mathrm{H}_{2}$ molar fraction of $0.02-0.08 \%$. The N/B-ratio was set to a value between 14 and 58 by adjusting the $\mathrm{NH}_{3}$ and TEB flows. The process temperature was varied in the range $800-1200{ }^{\circ} \mathrm{C}$, while the process pressure was kept at $10000 \mathrm{~Pa}$ (100 mbar) throughout the study. Typical growth time was 30 minutes. As substrates (111) oriented silicon samples were used. The silicon wafers were cut in approximately $2 \times 2 \mathrm{~cm}^{2}$ squares and cleaned using standard RCA cleaning [12] i.e. $\mathrm{NH}_{3}: \mathrm{H}_{2} \mathrm{O}_{2}: \mathrm{H}_{2} \mathrm{O}$ 1:1:5 followed by $\mathrm{HCl}_{2}: \mathrm{H}_{2} \mathrm{O}_{2}: \mathrm{H}_{2} \mathrm{O}$ 1:1:6 and rinsed in de-ionized water. Prior to loading, the substrate was dipped in diluted HF ( $\mathrm{HF}(48 \%): \mathrm{H}_{2} \mathrm{O} 1: 3$ ) to remove the native silicon oxide.

The thicknesses of the deposited films were determined using white light interferometry. The chemical bonding structure of the deposited films was analyzed by Fourier transform infrared (FT-IR) spectroscopy (Bio-Rad QS-2200) and X-ray diffraction (XRD), Philips powder diffractometer PW 1820 with Cu Ka radiation $(\lambda=1.5418 \AA$ ) in the Bragg-Brentano configuration was used to study the structural properties. The elemental composition of selected films was analyzed by time-of-flight energy elastic recoil detection analysis (ToF-E ERDA). The experimental details of the ToF-E ERDA can be found elsewhere [13].

The gas phase composition was modeled by a computer program based on free-energy minimization algorithms [14] with thermodynamical data taken from the JANAF thermochemical tables [15]. The $\mathrm{H}_{2}-\mathrm{BH}_{3}-\mathrm{C}_{2} \mathrm{H}_{4}-\mathrm{NH}_{3}$ system was studied since TEB is not available in this program and $\mathrm{BH}_{3}$ and $\mathrm{C}_{2} \mathrm{H}_{4}$ with a ratio of $1: 3$ were used instead as they 
were suggested to be the results of the dissociation of TEB [16]. Also the NH specie is not available in the program, thus for the decomposition of $\mathrm{NH}_{3}$ only $\mathrm{N}, \mathrm{N}_{2}, \mathrm{NH}_{2}$ and $\mathrm{N}_{2} \mathrm{H}_{2}$ are considered. No solid phases were allowed to form in the calculations.

\section{Results}

All deposited films were studied by FT-IR spectroscopy, a typical FT-IR spectrum is given in Fig. 2, the peaks seen at $1410 \mathrm{~cm}^{-1}$ and $815 \mathrm{~cm}^{-1}$ could be attributed to the strong in-plane stretching vibrations and weak out-of-plane bending vibrations of $\mathrm{sp}^{2}$ hybridized $\mathrm{BN}$ [4]. The typical feature of $\mathrm{sp}^{3}$ hybridized $\mathrm{BN}$, the $\mathrm{B}-\mathrm{N}-\mathrm{B}$ bending reported to be at $1050 \mathrm{~cm}^{-1}$ [4], was never detected. Thus the FT-IR results suggest that the $s p^{2}$ hybridized $\mathrm{BN}$ is formed during the deposition process. To investigate the growth conditions for $\mathrm{sp}^{2}$ hybridized BN films, the N/B ratio and the growth temperature were changed.



Figure 2: Typical FT-IR spectrum of a film deposited at the experimental condition of this study. 
N/B-ratio

$\mathrm{N} / \mathrm{B}$-ratio in the range from 14 to 58 was studied at $1000^{\circ} \mathrm{C}$ keeping the $\mathrm{B} / \mathrm{H}_{2}$ ratio constant at a value of $0.08 \%$. The X-ray diffraction patterns of some of these films are shown in Fig. 3 . No XRD peaks related to any phase of boron nitride can be detected in the diffractograms of the deposited films. Apart from the Si 111 peak at $28.4^{\circ}$, broad features around $21^{\circ}, 24^{\circ}$ and $42^{\circ}$ are found. These could be attributed to the 111 peak of $\mathrm{HBO}_{2}, 100$ and 110 peaks of $\mathrm{B}_{2} \mathrm{O}_{3}$, respectively. From the diffractograms it is apparent that the boron oxide peaks are of higher intensities at lower N/B-ratio. The deposition rate for such films was found to decrease with higher N/B-ratio, from $17 \mu \mathrm{m} / \mathrm{h}$ for $\mathrm{N} / \mathrm{B}=14$ to $6 \mu \mathrm{m} / \mathrm{h}$ for $\mathrm{N} / \mathrm{B}=58$. This was attributed to an increased etching of the film surface by the higher $\mathrm{NH}_{3}$ flow.

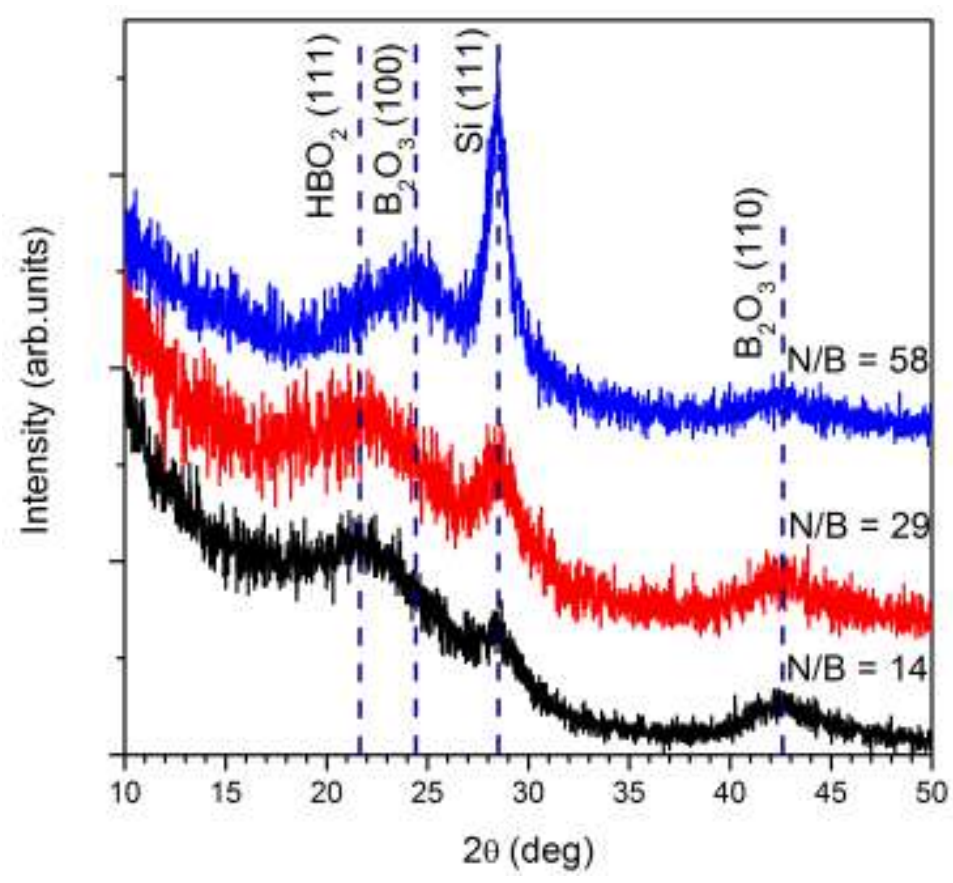

Figure 3: XRD diffractograms of films deposited at $1000{ }^{\circ} \mathrm{C}$ with $\mathrm{B} / \mathrm{H}_{2}=0.08 \%$ and different N/B ratios. 


\section{Process temperature}

The effect of the deposition temperature was studied in the range $800-1200^{\circ} \mathrm{C}$ with $\mathrm{N} / \mathrm{B}=$ 29 and the resulting diffractograms are given in Fig. 4. In the present experimental conditions, none of the studied temperatures yield any crystalline $\mathrm{BN}$. At $800^{\circ} \mathrm{C}$ there are no features in the diffractogram apart from the Si 111 peak detected at $28.4^{\circ}$. At $1000{ }^{\circ} \mathrm{C}$, broad features are also seen at $21^{\circ}$ and $42^{\circ}$, and as above these features are attributed to $\mathrm{HBO}_{2}$ 111 and $\mathrm{B}_{2} \mathrm{O}_{3} 110$, respectively. At $1200^{\circ} \mathrm{C}$ a sharp peak with high intensity observed at $25.4^{\circ}$ and a low intensity peak at $35.6^{\circ}$ appear, these peaks are attributed to the 111 planes of $\mathrm{Si}_{2} \mathrm{CN}_{4}$ and $\mathrm{SiCN}$, respectively, and suggest a reaction between the film and the substrate. The deposition rate was found to have a maximum of $10 \mu \mathrm{m} / \mathrm{h}$ at $1000^{\circ} \mathrm{C}$, the lower deposition rates at $800{ }^{\circ} \mathrm{C}(3 \mu \mathrm{m} / \mathrm{h})$ and at $1200{ }^{\circ} \mathrm{C}(6 \mu \mathrm{m} / \mathrm{h})$ were attributed to insufficient chemical efficiency and enhanced etching, respectively.

\section{Elemental composition}

The elemental composition measured by ToF-E ERDA of a sample deposited at $1000^{\circ} \mathrm{C}$ with $\mathrm{N} / \mathrm{B}=57$ and $\mathrm{B} / \mathrm{H}_{2}=0.02 \%$ was found to be 49 at $\%, 44$ at $\%, 4$ at $\%$ O, 3 at\% $\mathrm{C}$, not taking the hydrogen content of the film into account. The overall hydrogen content of the film was estimated to $4-5$ at\%. The experimental uncertainty for these elements is $1-1.5$ at $\%$. The oxygen content was found to be constant along the depth of the film and thus not an effect of surface oxides. 




Figure 4: XRD diffractograms of films deposited at different temperatures with $N / B=29$,

$\mathrm{B} / \mathrm{H}_{2}=0.08 \%$

\section{Thermodynamic modeling}

The gas phase composition, studied by thermodynamic calculations in the temperature interval $800-1250^{\circ} \mathrm{C}$ at $10000 \mathrm{~Pa}(100 \mathrm{mbar})$ with $\mathrm{N} / \mathrm{B}=30$ and $\mathrm{B} / \mathrm{H}_{2}=0.05 \%$, is shown in Fig. 5a. The most important boron species are found to be $\mathrm{BH}_{2}$ and $\mathrm{BH}_{3}$, while the nitrogen is most likely supplied by $\mathrm{NH}_{3}$. It has been reported that $\mathrm{N}_{2}$ and $\mathrm{HCN}$ molecules have very low reactivity and sticking coefficients in CVD of III-N's [17]. The effect of water on the gas phase composition at $1027^{\circ} \mathrm{C}$ with a varying, small amount of water added is shown in Fig. 5b. The calculations suggest that $\mathrm{BO}_{\mathrm{x}}$ and $\mathrm{HBO}_{\mathrm{x}}$ species are being formed and at high enough water contamination they even become the dominating boron species. This is an indication that 
the $\mathrm{B}-\mathrm{O}$ bonds are being formed already in the gas phase when oxygen contamination exists and that the $\mathrm{BO}_{\mathrm{x}}$ and $\mathrm{HBO}_{\mathrm{x}}$ species are the likely sources of oxygen impurities.
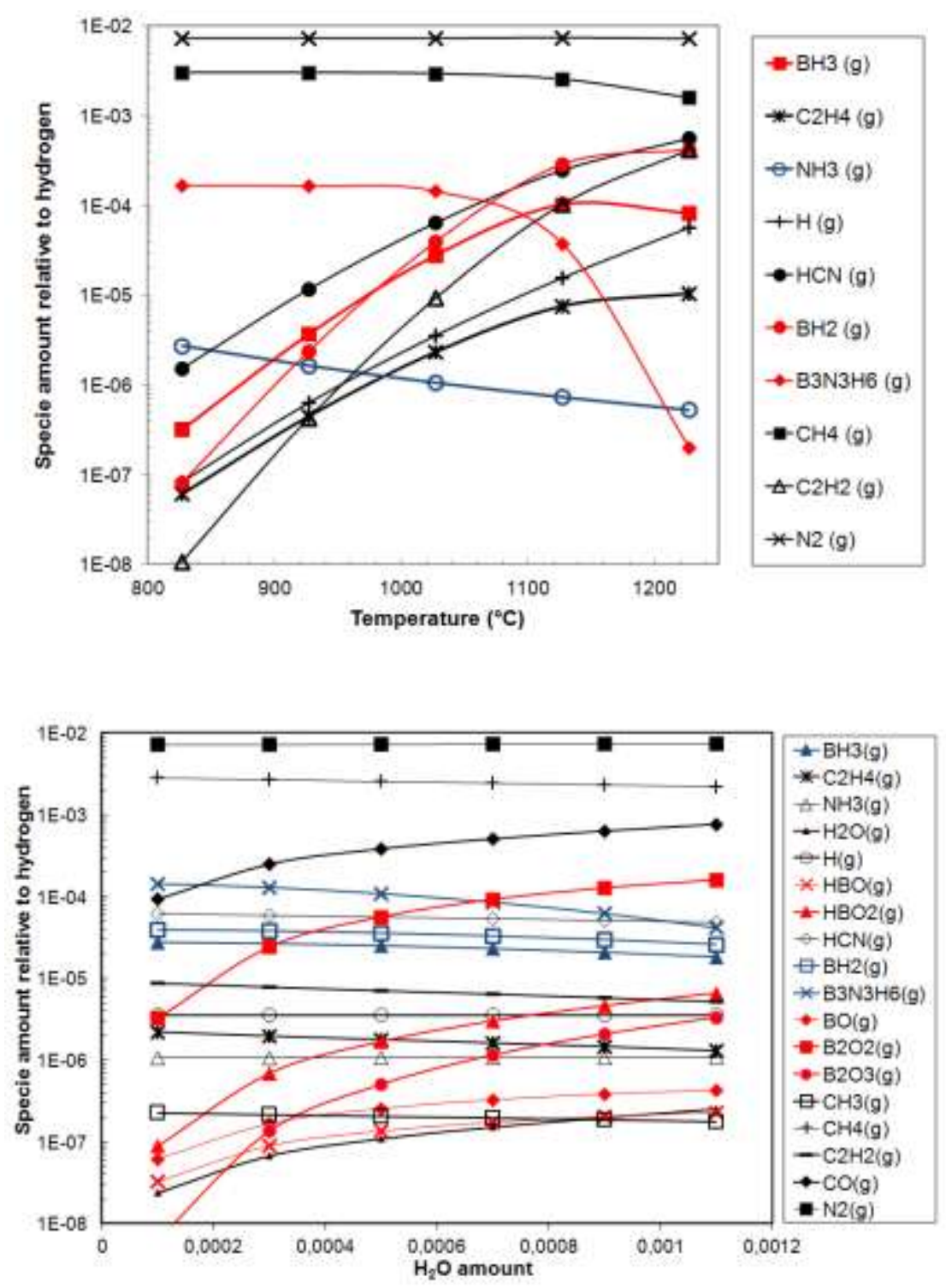

Figure 5: Calculated gas phase composition at (a) different process temperatures without any oxygen contaminations, (b) at $1027^{\circ} \mathrm{C}$ with various amount of oxygen contaminations added to the gas mixture. For all calculations $\mathrm{N} / \mathrm{B}=30$ and $\mathrm{B} / \mathrm{H}_{2}=0.05 \%$ were used. 
Effect of moisture after deposition

The deposited films were found to be sensitive to moisture; after two months exposure to air and sunlight the film surface had changed significantly, visible even to the naked eye, optical microspore revealed a surface with small crystals (Fig. 6a). The films were analyzed by XRD (Fig. 6b) which suggested that the film had reacted with moisture in the air to form boric acid, $\mathrm{B}(\mathrm{OH})_{3}$, as indicated by the peaks at $15^{\circ}$ and $58^{\circ}$, attributed to the $010 / 100$ and 004 peaks of $\mathrm{B}(\mathrm{OH})_{3}$ respectively.

\section{Discussion}

The presence of the typical peaks related to $\mathrm{sp}^{2}$-hydbridized BN in the FT-IR spectrum presented in Fig. 2 indicates that the films deposited in this study contains $\mathrm{sp}^{2}$-hybridized BN, i.e. h-BN, r-BN, t-BN or amorphous BN. It should be noticed that although the FT-IR spectrum for $\mathrm{sp}^{2}$-hybridized BN is similar to FT-IR spectra of boric acid, FT-IR of boric acid also include a strong, sharp peak at $1195 \mathrm{~cm}^{-1}$ [18]. Since this peak is not present in the spectra of our as grown samples, our FT-IR supports that $\mathrm{sp}^{2}-\mathrm{BN}$ is deposited. Further support is found from the ToF-E ERDA analysis that indicates a close to 1:1 composition with respect to the boron and nitrogen content $(B / N=1.1)$ for the films. In $X R D$, no peaks related to any phase of BN, not even the less ordered t-BN could be found (Figs. 3 and 4). This indicates difficulties in depositing crystalline BN films at applied conditions. However, the literature shows that the growth of crystalline h-BN is possible in temperature range 800 $1200{ }^{\circ} \mathrm{C}[8,9]$, albeit with a higher N/B-ratio. This suggests that the formation of crystalline $\mathrm{BN}$ is disturbed in our process. The peaks found in XRD, except for the peaks related to the $\mathrm{Si}$ substrate and phases related to reactions with the substrate, are attributed to boron oxides 

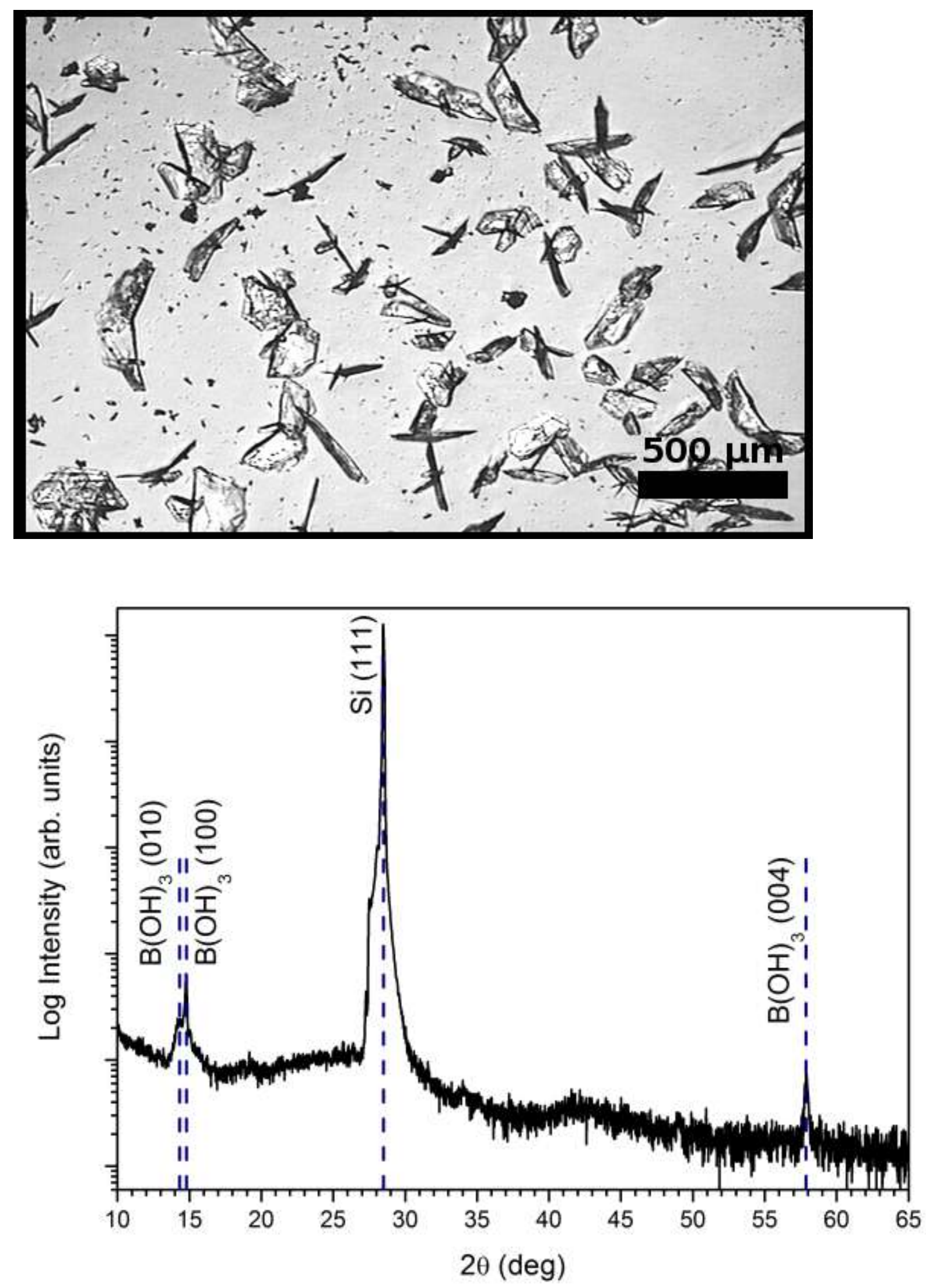

Figure 6: Optical microscope image (a) and XRD diffractogram (b) of a film, deposited with $\mathrm{N} / \mathrm{B}=29, \mathrm{~B} / \mathrm{H}_{2}=0.08 \%$ at $1000^{\circ} \mathrm{C}$, after exposure to air and sunlight for two months. 
and hydrogen borate and they are all very broad and of low intensity. This suggests that crystalline oxides of low crystalline quality and/or very small crystallites are formed while the deposited boron nitride is X-ray amorphous.

The observed sensitivity to moisture after the deposition has been reported earlier for BN films synthesized by both CVD and PECVD, especially for amorphous films and films of low crystalline quality $[5,19,20,21,22]$. The fact that the films deposited in this study show similar sensitivity towards moisture again suggests that they are amorphous BN films.

An explanation could be that it is difficult to deposit crystalline BN in the presence of water and/or oxygen. As suggested by the calculations presented in Fig. 5, the presence of water leads rapidly to the formation of species with B-O bonds in the gas phase. The higher covalent bond strength for $\mathrm{B}-\mathrm{O}$ bonds, compared to $\mathrm{B}-\mathrm{N}$ bonds [23] suggests that once the $\mathrm{B}$ $\mathrm{O}$ bonds are formed, it is unlikely that the oxygen will be replaced by nitrogen. It is further well known that boron has a strong affinity towards oxygen, which gives rise to the rich chemistry of the borates [24]. Thus in the presence of oxygen, boron will preferably form B$\mathrm{O}$ bonds already in the gas phase, leading to incorporation of oxygen in the BN lattice which disturbs the lattice and results in an amorphous film. It is likely that the oxygen is first incorporated in the films as boron hydroxides which are subsequently dehydrated to form the oxides.

The source of oxygen in the process is most likely water since at a base pressure in the $10^{-4}$ $\mathrm{Pa}\left(10^{-6} \mathrm{mbar}\right)$ range, i.e. in the high vacuum range, the residual gas is mainly water. Since the hydrogen carrier gas used in the experiments was purified by a palladium membrane, and the precursor gases, TEB and $\mathrm{NH}_{3}$, are of very high purity, the most likely source of water 
in our experiments is the hot pressed h-BN parts in the susceptor (Fig. 1). To circumvent the oxygen contaminations, experiments with a SiC coated graphite susceptor were done. The boron nitride films deposited in such a SiC-coated susceptor, even at $1500^{\circ} \mathrm{C}$, had a very low carbon and oxygen content close to the detection limit of the used experimental technique [25].

\section{Concluding remarks}

From ToF-E ERDA, the films are slightly boron rich boron nitride; FT-IR experiments indicate that the films consist of a $\mathrm{sp}^{2}$-hybridized BN phase. However, the XRD analysis shows that the films are amorphous with incorporated boron oxides. Due to their amorphous and low quality nature, the synthesized films were found to be sensitive to moisture which rendered a reaction to form boric acid.

The presence of water and/or oxygen during the deposition of boron nitride leads to oxygen incorporation via species containing a strong B-O bond, which are formed already in the gas phase. The incorporation of oxygen in the films prohibits the growth of high quality boron nitride.

\section{Acknowledgements}

Dr. Ivan Ivanov is gratefully acknowledged for assistance with the white light interferometry measurements. The Swedish Research Council (VR 621-2009-5264) is gratefully acknowledged for financial support. 


\section{References}

[1] D. M. Hoffman, G. L. Doll, P. C. Eklund, Phys. Rev. B 30 (1984) 6051

[2] L. Duclaux, B. Nysten, J. P. Issi, A. W. Moore, Phys. Rev. B 46 (1992) 3362

[3] R. T. Paine, C. K. Narula, Chem. Rev. 90 (1990) 73

[4] P. B. Mirkarimi, K. F. McCarty, D. L. Medlin, Mater. Sci. Eng. R 21 (1997) 47

[5] W. J. Zhang, Y. M. Chong, I. Bello, S. T. Lee, J. Phys. D 40 (2007) 6159

[6] I. Konyashin, J. Bill, F. Aldinger, Chem. Vap. Deposition 3 (1997) 239

[7] W. Kulisch, R. Freudenstein, Thin Solid Films 516 (2007) 216

[8] Y. Kobayashin, T. Akasaka, J. Cryst. Growth 310 (2008) 5044

[9] Y. Kobayashin, T. Akasaka, T. Makimoto, J. Cryst. Growth 310 (2008) 5048

[10] A. Henry, J. Hassan, J. P. Bergman, C. Hallin, E. Janzén, Chem. Vap. Deposition 12 (2006) 475

[11]E. Janzén, J.P. Bergman, Ö. Danielsson, U. Forsberg, C. Hallin, J. Hassan, A. Henry, I.G. Ivanov, A. Kakanakova-Georgieva P. Persson, Q. ul Wahab, Mater. Sci. Forum 483-485 (2005) 61

[12] W. Kern, D. A. Puotinen, RCA Review, June (1970) p. 187

[13] M. Junaid, D. Lundin, J. Palisaitis, C.-L. Hsiao, V. Darakchieva, J. Jensen, P. O. A. Persson, P. Sandstrom, W.-J. Lai, L.-C. Chen, K.-H. Chen, U. Helmersson, L. Hultman, J. Birch, J. Appl. Phys. 110 (2011) 123519.

[14] B. Nolang, Ekvi System 3.01 from Svensk Energi Data, Department of Inorganic Chemistry, Uppsala University, Sweden. 
[15 ] NIST-JANAF Thermochemical Tables (Online). Available: http://kinetics.nist.gov/janaf/ (2012, April 19)

[16] J. S. Lewis, S. Vaidyaraman, W. J. Lackey, P. K. Agrawal, G. B. Freeman, E. K. Barefield, Matter. Lett. 27 (1996) 327

[17] Ö. Danielsson, E. Janzén, J. Cryst. Growth 253 (2003) 26

[18] E. F. Medvedev, A. S. Komarevskaya, Glass and Ceramics 64 (2007) 42

[19] M. J. Rand, J. F. Roberts, J. Electrochem. Soc. 115 (1968) 423

[20] J. Kouvetakis, V. V. Patel, C. W. Miller, D. B. Beach, J. Vac. Sci. Tech. A 8 (1990) 3929

[21] G. F. Cardinale, P. B. Mirikarimi, K. F. McCarty, E. J. Klaus, D. L. Medlin, W. M. Clift, D. G. Howitt, Thin Solid Films 253 (1994) 130

[22] C. G. Cofer, J. Economy, Carbon 33 (1995) 389

[23] M. Sana, G. Leroy, C. Wilante, Organometallics 11 (1992) 781

[24] N. N. Greenwood, A. Earnshaw, Chemistry of the Elements 2nd ed, 2005, Elsevier,

Oxford

[25] M. Chubarov, H. Pedersen, H. Högberg, V. Darakchieva, J. Jensen, P. O. Å. Persson, A. Henry, Phys. Stat. Sol. RRL 5 (2011) 397 